\title{
A Comprehensive Evaluation of Policy Effectiveness for Energy Efficiency in Existing Buildings
}

\begin{abstract}
The healthy and stable development of energy efficiencies in existing buildings cannot be separated from effective policy operation, and evaluating policy effectiveness contributes to scientifically-sound government decision-making. This paper creates an evaluation index system and a grey comprehensive evaluation model for policy effectiveness for energy efficiency in existing buildings using three dimensions: 1) the effect of the policy itself; 2) the administrative effect of the policy; and 3) policy implementation effects. It chooses the government's subsidy policy and preferential tax policy at market cultivation stage for its empirical comparative evaluation. The evaluation indicates that the former is more effective. Finally, it puts forward policy development suggestions from the perspective of: 1) clarifying incentive object; 2) broadening incentive scope; 3) increasing incentive intensity; and 4) innovating incentive mode.
\end{abstract}

Keywords: existing buildings, energy efficiency, policies effectiveness, grey comprehensive evaluation

\section{Introduction}

\subsection{Background}

China's buildings cover an area of more than 43 billion square meters. According to existing building energy efficiency standards, the percent of non-energy efficiency buildings is as high as $95 \%$ (Zhang \& Wang, 2008). This serious situation of large stock and high energy consumption of existing buildings has drawn great attention. The government adopted a variety of policy means and policy

Manuscript received June 10, 2014; accepted October 20, 2014

Xing Wei ( $₫)$, Han-ding Guo

School of Economics and Management, Tianjin Chengjian University, Tianjin 300384, China

Email: weixing10160417@163.com tools to encourage businesses to have energy efficiency in existing buildings (hereinafter referred to as EEEB). The process of EEEB relates to economic and social sustainable development. The scientific formulation and effective implementation of EEEB policy has great significance to guide and promote the development of an energy efficiency market (Wei \& Guo, 2014). To ensure the market's healthy and orderly development, the authors must evaluate the operating state of EEEB market under the policies and the policies effectiveness.

\subsection{Brief literature review}

Research on policy effectiveness for EEEB, both domestic and overseas, focuses on a hierarchy policy relationship (Ma, Li, \& Qi, 2012; Yang, 2006), Energy Management Contracting (EMC) policy (Bertoldip, 2006; Guo, Ma, \& Shang, 2012; Milou \& Niels, 2007), externality-based building incentive policy ( $\mathrm{Lu}, 2007)$; information asymmetry (Han, Liu, Zhang, \& Jin, 2009; Xu, Guo, \& Ren, 2009); and policy combinations (Carlsson-Kanyama, Linden, \& Eriksson, 2005).

At present, policy evaluation mainly concentrates on the evaluation of policy performance. By analyzing and evaluating the implementation effects of existing economic incentive policies, Milou and Niels (2007) pointed out that preferential tax policy is an effective means of eliminating the economic externality of EEEB, and the developing directions for economic incentive polices. Jeffery, A. Drezner compared and analyzed a number of policies from numerous countries, such as: management and supervision policy; technical support policy; economic incentive policy and propaganda and training policies. It turned out that the economic incentive policy has a good promoting effect, the preferential tax policy can cover more range, and the subsidy policy and the relief policy can play a leading role in the energy efficiency work, and that the economic incentive policies might be an important direction of future policy (Jeffery \& Drezner, 1999). A 
comprehensive multi-index evaluation model of economic incentive policies of building energy efficiency should intensify five aspects: 1) utility maximization of energy utilization in buildings; 2) efficiency of incentive policy; 3 ) equity of incentive policy; 4) cooperation mechanism of incentive policy; 5) acceptability of incentive policy. They evaluated the effects of the economic incentive polices. The model provided a reference for extending the implementation life of a mature policy or terminating it or further optimizing it.

Of existing research results, most of which are qualitative evaluations, at present, there is not a complete and mature evaluation method and system of policy effectiveness for EEEB. In consequence, it is difficult to measure policy effects for EEEB systematically. On the basis previous studies, this paper advances a theory of policy effectiveness for EEEB, builds a multi-level evaluation index system for it; establishes a grey comprehensive evaluation model based upon grey system theory; and makes scientific judgment regarding whether the policy is effective and to what degree.

\section{Theoretical analyses on policy effectiveness evaluation of EEEB}

\subsection{Connotation of EEEB policy effectiveness}

There is not now a unified and precise definition for connoting policy effectiveness for EEEB. In this paper, the authors hold the view that it means performance and value of policy in short words. The connotation also means matching degree of implementation effect to target of the policy, and represents effect of policy to achieve the desired objectives.

The connotation of policy effectiveness of EEEB includes two meanings: the one is whether the policy itself is reasonable, that means the effect of policy itself, which includes policy goal, policy object, policy structure, policy content. The other is that effectiveness is not limited only to the policy itself, the more is to consider the implementation effect and management effect. Measuring whether the policy is effective and its degree of significance needs to consider two factors: the policy itself; and policy implementation.

\subsection{Connotation of EEEB policy effectiveness evaluation}

Connotation of policy effectiveness evaluation of EEEB means a process of using scientific technology and method to evaluate the effect a policy has according to certain standards and procedures. Using such an evaluation, the authors can diagnose policy effects scientifically. And it can provide important bases for continuing, amending, or stopping a policy (James, 2004).

\section{Constructing an index system for evaluating EEEB policy effectiveness}

\subsection{Setting up evaluation index}

Establishing of an evaluation index system follows the principle of objectivity, systematization, comprehensiveness, justice and dynamic design. It applies the principle and method of system evaluation to confirm the index system synthetically (Zhang, Guo, Guo, \& Wang, 2009).

EEEB is complex and systematic engineering involving many stakeholders and the relationship between them is complicated. Setting up an index system should consider various factors from multiple perspectives finally it can form a multilevel, multi-angle and all-around evaluation index system. Analyzing current situation of EEEB market in China, the paper builds evaluation index system from three aspects: 1) implementation effect of EEEB policy (including economic indexes and energy indexes); 2) the effect of policy itself; and 3) any management effects of the policy.

EEEB market is the most direct action object of EEEB policy, whose indicators are the best response to policy implementation effect. Under the first level indexImplementation effect of EEEB policy $\left(U_{1}\right)$, the authors chose economic indexes: 1) average annual growth rate of total output value of energy service industry $\left(U_{11}\right)$; 2) economic contribution of EEEB $\left.\left(U_{12}\right) ; 3\right)$ average annual growth rate of transformation area $\left(U_{13}\right)$ and 4$)$ two energy indexes: A) energy saving rate after transformation $\left(U_{14}\right)$, and B) energy consumption per unit of GDP $\left(U_{15}\right)$.

As internal reason, the effect of policy itself also decides the policy effectiveness. Under the first level index effect of policy itself $\left(U_{2}\right)$, the authors set up five secondary level indices: 1) completeness of policy system $\left.\left(U_{21}\right) ; 2\right)$ definiteness of policy goal $\left.\left(U_{22}\right) ; 3\right)$ suitability of policy content $\left.\left(U_{23}\right) ; 4\right)$ operability of policy tools $\left(U_{24}\right)$; and 5) dynamic property of policy update $\left(U_{25}\right)$.

Exerting the policy effect cannot be done without a $100 \%$ executive force and regulatory force, so administrative ability is also an important index reflecting the policy efficiency. Under the first level index - management effect of policy $\left(U_{3}\right)$, the authors choose five secondary level indexes: 1) proportion of management institutions of energy saving $\left.\left(U_{31}\right), 2\right)$ transparency of management $\left.\left(U_{32}\right) ; 3\right)$ simplified degree of management $\left(U_{33}\right)$; 4) elasticity of policy implementation $\left(U_{34}\right)$; and $5)$ people's satisfaction of management $\left(U_{35}\right)$.

Using this, the authors get an index set for the policy effectiveness evaluation of EEEB, as follows.

$$
\begin{gathered}
U=\left\{U_{1}, U_{2}, U_{3}\right\} \\
U_{1}=\left\{U_{11}, U_{12}, U_{13}, U_{14}, U_{15}\right\}
\end{gathered}
$$




$$
\begin{aligned}
& U_{2}=\left\{U_{21}, U_{22}, U_{23}, U_{24}, U_{25}\right\} \\
& U_{3}=\left\{U_{31}, U_{32}, U_{33}, U_{34}, U_{35}\right\}
\end{aligned}
$$

\subsection{Confirming weight of evaluation index}

Presently, methods to determine index weight by researchers include, among others: 1) analytic Hierarchy Process (AHP); 2) entropy Method; and 3) principal Component Analysis (PCA); and 4) coefficient variation method, Importance ranking method. Among them, methods 2, 3, and 4 need much data for support. However, EEEB has just begun in our country so there is dependence to valuator, so it is be chosen in the paper. The key to applying the method is ranking the indexes by their degree of importance and order accurately. Therefore, we chose industry leading experts to rank the indexes paper selected. Then through theoretical research and optimization experiment, the authors know the importance degree after ranking presents a phenomenon of geometric progression. Here is the relationship between the optimum of common ratio and index number: $\frac{1}{2}, \frac{2}{3}, \frac{3}{5}, \frac{5}{8}, \frac{8}{13}, \frac{13}{21} \ldots$, When the index number is equal to the denominator of common ratio above, the common ratio is the fractional value that the denominator corresponds to. If the index number is between the two denominators, the common ratio is the numerical value of the golden section point $(0.618)$ between the two fractional values (Yang, Hui, \& Zhang, 2012). Calculation formula of index weight is as follows.

$$
\begin{aligned}
A & =\left(a_{1}, a_{2}, \cdots a_{n}\right) \\
& =\left(\sum_{i=1}^{n} a^{i}\right)^{-1}\left(a, a^{2}, \cdots a^{n}\right) \quad \text { (Formula 1) }
\end{aligned}
$$

Remarks: $n$ is evaluation index number; $a$ is common ratio.

According to the Formula 1, the authors calculate weight of every evaluation index and finally get the weight of evaluation index system, which is shown in Table 1.

\section{Construction of Grey comprehensive evaluation model on policy effectiveness of EEEB}

4.1 Analysis of applicability of the Grey comprehensive evaluation model

The Grey system has the following characteristics: 1) incomplete information which means it has known information and unknown information; 2) fuzzy structure and dynamic random change; and 3) the evaluation index system is layered and index data is incomplete. In this study, evaluation system for EEEB policy is a Grey system. First reason, academic research on policy effectiveness of EEEB is not mature and the influence of factors and mechanisms on effectiveness is not clear. Second, the EEEB market is in the field of market failure due to economic externality and information asymmetry. Third, a

\begin{tabular}{|c|c|c|c|c|}
\hline$\overline{\text { Goal }}$ & The first level index & Weight & The secondary level index & Weight \\
\hline \multirow{15}{*}{$\begin{array}{l}\text { Index system of policy } \\
\text { effectiveness evaluation } \\
\text { of EEEB }\end{array}$} & \multirow{6}{*}{$\begin{array}{l}\text { Implementation effect of EEEB } \\
\text { policy }\left(U_{1}\right)\end{array}$} & \multirow{6}{*}{0.473} & $\begin{array}{c}\text { Average annual growth rate of total output value of energy } \\
\text { service industry }\left(U_{11}\right)\end{array}$ & 0.43 \\
\hline & & & Economic contribution of EEEB $\left(U_{12}\right)$ & 0.26 \\
\hline & & & Average annual growth rate of transformation area $\left(U_{13}\right)$ & 0.16 \\
\hline & & & Energy saving rate after transformation $\left(U_{14}\right)$ & 0.09 \\
\hline & & & Energy consumption per unit of GDP $\left(U_{15}\right)$ & 0.06 \\
\hline & & & Completeness of policy system $\left(U_{21}\right)$ & 0.43 \\
\hline & \multirow{4}{*}{ Effect of policy itself $\left(U_{2}\right)$} & \multirow{4}{*}{0.316} & Definiteness of policy goal $\left(U_{22}\right)$ & 0.26 \\
\hline & & & Suitability of policy content $\left(U_{23}\right)$ & 0.16 \\
\hline & & & Operability of policy tools $\left(U_{24}\right)$ & 0.09 \\
\hline & & & Dynamic property of policy update $\left(U_{25}\right)$ & 0.06 \\
\hline & \multirow{5}{*}{$\begin{array}{l}\text { Management effect of policy } \\
\qquad\left(U_{3}\right)\end{array}$} & \multirow{5}{*}{0.211} & Proportion of management institutions of energy saving $\left(U_{31}\right)$ & 0.43 \\
\hline & & & Transparency of management $\left(U_{32}\right)$ & 0.26 \\
\hline & & & Simplified degree of management $\left(U_{33}\right)$ & 0.16 \\
\hline & & & Elasticity of policy implementation $\left(U_{34}\right)$ & 0.09 \\
\hline & & & People's satisfaction of management $\left(U_{35}\right)$ & 0.06 \\
\hline
\end{tabular}
part of the evaluation index data in this research can be

Table 1

Index System of Policy Effectiveness Evaluation of EEEB 
collected and others not. Fourth reason, there are both quantitative indices (whiten index) and qualitative index (grey index). This article adopts the Grey model for evaluation.

The Grey comprehensive evaluation model is based on the mathematical principle of Grey clustering. The Grey whitening weight function can judge the category of objects according to the observed value of evaluation index; moreover it can be used for describing "preference" degree that a grey number to different numerical within its scope (Chen, 2012). So this article adopts the Grey whitening weight function for evaluation.

\subsection{Implementation process of evaluation}

(1) Confirming standard of evaluation grade. All indexes will be divided into five grades: 1) excellent; 2) good; $3)$ medium; 4) poor; and 5) very poor, and will be evaluated and scored of 5, 4, 3, 2, 1 in turn. The index between the two adjacent levels will be evaluated 4.5, 3.5, 2.5, and 1.5. All scores will be confirmed by experts according to their experience.

(2) Confirming score matrix. According to evaluation standard, experts score each index, and then get the score matrix. We hypothesize that $x_{i j p}(i=1,2 \ldots m ; j=1,2 \ldots n ; p$ $=1,2 \ldots k)$ is the score of evaluation index $x_{i j}$ scored by expert $p$. So the authors get the score matrix $D$.

$$
D=\left[\begin{array}{llll}
x_{111} & x_{112} & \cdots & x_{11 p} \\
x_{121} & x_{122} & \cdots & x_{12 p} \\
\vdots & \vdots & & \vdots \\
x_{i j 1} & x_{i j 2} & \cdots & x_{i j 3} \\
\vdots & \vdots & & \vdots \\
x_{351} & x_{352} & \cdots & x_{353}
\end{array}\right]
$$

(3) Confirming evaluation grey class. The paper sets five evaluation grey classes: $m=1, m=2, m=3, m=4, m=5$ which in turn represent very poor, poor, medium, good, excellent. The corresponding Grey whitening weight function is expression formula 1 to 5 below.

1) Grey class $m=1$, grey number $\otimes \in[0,1,2]$, the Grey whitening weight function is $f_{1}$.

$$
f_{1}\left(x_{i j p}\right)= \begin{cases}1, & x_{i j p} \in[0,1] \\ 2-x_{i j p}, & x_{i j p} \in[1,2] \\ 0, & x_{i j p} \notin[0,2]\end{cases}
$$

(Expression formula 1)

2) Grey class $m=2$, grey number $\otimes \in[0,2,4]$, the Grey whitening weight function is $f_{2}$.

$$
f_{2}\left(x_{i j p}\right)= \begin{cases}x_{i j p} / 2, & x_{i j p} \in[0,2] \\ \left(4-x_{i j p}\right) / 2, & x_{i j p} \in[2,4] \\ 0, & x_{i j p} \notin[0,4]\end{cases}
$$

(Expression formula 2)

3) Grey class $m=3$, grey number $\otimes \in[0,3,6]$, the Grey whitening weight function is $f_{3}$.

$$
f_{3}\left(x_{i j p}\right)= \begin{cases}x_{i j p} / 3, & x_{i j p} \in[0,3] \\ \left(6-x_{i j p}\right) / 3, & x_{i j p} \in[3,6] \\ 0, & x_{i j p} \notin[0,6]\end{cases}
$$

(Expression formula 3)

4) Grey class $m=4$, grey number $\otimes \in[0,4,8]$, the Grey whitening weight function is $f_{4}$.

$$
f_{4}\left(x_{i j p}\right)= \begin{cases}x_{i j p} / 4, & x_{i j p} \in[0,4] \\ \left(8-x_{i j p}\right) / 4 & x_{i j p} \in[4,8] \\ 0, & x_{i j p} \notin[0,8]\end{cases}
$$

(Expression formula 4)

5) Grey class $m=5$, grey number $\otimes \in[5, \infty]$, the Grey whitening weight function is $f_{5}$.

$$
f_{5}\left(x_{i j p}\right)= \begin{cases}x_{i j p} / 5, & x_{i j p} \in[0,5] \\ 1, & x_{i j p} \in[5,+\infty] \\ 0, & x_{i j p} \notin[0,+\infty]\end{cases}
$$

(Expression formula 5)

(4) Calculating grey evaluation coefficient. Collecting and summarizing the expert mark sheet, and then the authors can calculate grey evaluation coefficient. To evaluation index $U_{i j}$, the grey evaluation coefficient belonging to the $m$ grey class is $X_{i j m}$, and the total evaluation coefficient is $X_{i j}$. So the formulas are as follows.

$$
\begin{aligned}
X_{i j m} & =\sum_{p=1}^{k} f_{m}\left(x_{i j p}\right) \\
& =f_{m}\left(x_{i j 1}\right)+f_{m}\left(x_{i j 2}\right)+\cdots+f_{m}\left(x_{i j p}\right) \\
X_{i j} & =\sum_{m=1}^{5} X_{i j m} \\
& =X_{i j 1}+X_{i j 2}+X_{i j 3}+X_{i j 4}+X_{i j 5}
\end{aligned}
$$

(Formula 3) 
(5) Confirming evaluation weight matrix. To evaluation index $U_{i j}$, the grey evaluation weight belonging to the $m$ grey class is $r_{i j m}$, and $r_{i j m}=\frac{X_{i j m}}{X_{i j}}$. So to $U_{i j}$, the grey evaluation weight vector belonging to all grey classes is $r_{i j}$, and $r_{i j}=\left(r_{i j 1}, r_{i j 2}, r_{i j 3}, r_{i j 4}, r_{i j 5}\right)$.

After gathering the grey evaluation weight vectors of all secondary level index $U_{i j}$ which is under every level index $U_{i}$, we can get the evaluation weight matrix $R_{i}$.

$$
R_{i}=\left[\begin{array}{l}
r_{i 1} \\
r_{i 2} \\
\vdots \\
r_{i j}
\end{array}\right]=\left[\begin{array}{llll}
r_{i 11} & r_{i 12} & \cdots & r_{i 15} \\
r_{i 21} & r_{i 12} & \cdots & r_{i 15} \\
\vdots & \vdots & & \vdots \\
r_{i i 1} & r_{i j 2} & \cdots & r_{i j 5}
\end{array}\right]
$$

(6) Implementing comprehensive evaluation. Comprehensive evaluation result of goal $U$ is composed of all subordinate first level indexes. Firstly we evaluate the first level index $U_{i}$, and get the evaluation results expressed by $B_{i}$, and $B_{i}=W_{i} \cdot R_{i}=\left(b_{i 1}, b_{i 2}, b_{i 3}, b_{i 4}, b_{i 5}\right)$. After synthesizing the evaluation results of the first level index, we can get the comprehensive evaluation of $U$ which denoted by $B$, and $B=W \cdot R=\left(b_{1}, b_{2}, b_{3}, b_{4}, b_{5}\right)$.

(7) Calculating comprehensive evaluation value. The comprehensive evaluation value is expressed by $A$, and $A=B \cdot C^{\mathrm{T}}$. In this formula, $C$ is a valuation vector formed by grey class according to grey level, and $C=\left(c_{1}, c_{2}, c_{3}, c_{4}, c_{5}\right)$. According to the final score, we classify the evaluation results, and finally get the conclusion of policy effectiveness degree. At this point, the evaluation process ends.

\section{An empirical research}

EEEB has just begun in China, and a distinguishing feature is that the EEEB market is in it initial stages. The government has issued a series of economic incentive polices, such as subsidy policy, preferential tax policy and preferential credit policy to encourage related subjects to support EEEB. However, what kind of incentive policy is should be give priority to in the cultivation stage, in other words, which is more effective of the most common policies: subsidy and preferential tax, has been the focus of academic research. In order to provide reference for policy building, in this paper the authors will compare the effectiveness of subsidy policy (hereinafter referred to as "policy 1") and preferential tax policy (hereinafter referred to as "policy 2") in cultivation stage.

\subsection{Evaluation process}

On the basis of the grey model, policies effectiveness will be divided into five grades: excellent, good, medium, poor, very poor, and will be evaluated and given value of 5, 4, 3, 2, 1 in turn. We invite five leading experts within the EEEB industry to score the two policies respectively. The scoring results are shown in Table 2.

In Table 2: $E_{1}$ is short for expert 1, others similarly.

According to implementation step in 4.2, the authors can get the evaluation weight matrix denoted by $R_{1}, R_{2}$, and $R_{3}$ of the first level index.

According to implementation step in 4.2, we can get the evaluation weight matrix denoted by $R_{1}, R_{2}$, and $R_{3}$ of the first level index.

Table 2

Summary Table of Experts' Scores

\begin{tabular}{|c|c|c|c|c|c|c|c|c|c|c|c|c|c|}
\hline Object & Index & $E_{1}$ & $E_{2}$ & $E_{3}$ & $E_{4}$ & $E_{5}$ & Object & Index & $E_{1}$ & $E_{2}$ & $E_{3}$ & $E_{4}$ & $E_{5}$ \\
\hline & $U_{11}$ & 5 & 3.5 & 4 & 4.5 & 3 & & $U_{11}$ & 4 & 4.5 & 4 & 3 & 3 \\
\hline & $U_{12}$ & 4 & 4 & 4.5 & 5 & 4 & & $U_{12}$ & 5 & 3 & 3 & 3.5 & 4 \\
\hline & $U_{13}$ & 5 & 5 & 3.5 & 3.5 & 4 & & $U_{13}$ & 5 & 3 & 3 & 3 & 3 \\
\hline & $U_{14}$ & 4 & 4 & 3 & 3 & 3.5 & & $U_{14}$ & 3 & 4 & 4 & 4 & 4 \\
\hline & $U_{15}$ & 5 & 4 & 3 & 3 & 3 & & $U_{15}$ & 4 & 2 & 3 & 2 & 4 \\
\hline & $U_{21}$ & 5 & 3 & 5 & 3 & 3.5 & & $U_{21}$ & 5 & 4 & 2 & 3 & 3 \\
\hline & $U_{22}$ & 4 & 4 & 3 & 3.5 & 3 & & $U_{22}$ & 4 & 3 & 3 & 5 & 2 \\
\hline \multirow[t]{8}{*}{ Policy 1} & $U_{23}$ & 4 & 3.5 & 4.5 & 5 & 3.5 & Policy 2 & $U_{23}$ & 4 & 3 & 3 & 2 & 3 \\
\hline & $U_{24}$ & 5 & 4.5 & 4 & 3.5 & 3 & & $U_{24}$ & 3 & 3 & 4 & 3 & 3 \\
\hline & $U_{25}$ & 4.5 & 3 & 3.5 & 5 & 3 & & $U_{25}$ & 3.5 & 2.5 & 3.5 & 3.5 & 3 \\
\hline & $U_{31}$ & 3.5 & 4.5 & 4 & 4 & 3.5 & & $U_{31}$ & 3 & 3.5 & 3.5 & 2.5 & 3.5 \\
\hline & $U_{32}$ & 3 & 4 & 4 & 4 & 4 & & $U_{32}$ & 2 & 4 & 3 & 3 & 3 \\
\hline & $U_{33}$ & 4 & 4.5 & 5 & 4 & 3.5 & & $U_{33}$ & 3 & 3.5 & 3 & 3 & 2.5 \\
\hline & $U_{34}$ & 3.5 & 3.5 & 4 & 4.5 & 3 & & $U_{34}$ & 3 & 4 & 3.5 & 2.5 & 2 \\
\hline & $U_{35}$ & 5 & 3 & 3.5 & 3 & 3.5 & & $U_{35}$ & 2 & 2.5 & 4 & 3.5 & 3 \\
\hline
\end{tabular}




$$
\begin{gathered}
R_{1}=\left[\begin{array}{l}
r_{11} \\
r_{12} \\
r_{13} \\
r_{14} \\
r_{15}
\end{array}\right]=\left[\begin{array}{lllll}
0, & 0.061, & 0.270, & 0.345, & 0.324 \\
0, & 0, & 0.241, & 0.393, & 0.366 \\
0, & 0.42, & 0.251, & 0.356, & 0.351 \\
0, & 0.094, & 0.313, & 0.329, & 0.264 \\
0, & 0.115, & 0.305, & 0.305, & 0.275
\end{array}\right] \\
R_{2}=\left[\begin{array}{l}
r_{21} \\
r_{22} \\
r_{23} \\
r_{24} \\
r_{25}
\end{array}\right]=\left[\begin{array}{lllll}
0, & 0.01, & 0.279, & 0.309, & 0.311 \\
0, & 0.094, & 0.313, & 0.329, & 0.264 \\
0, & 0.041, & 0.261, & 0.360, & 0.338 \\
0, & 0.061, & 0.270, & 0.345, & 0.324 \\
0, & 0.098, & 0.288, & 0.315, & 0.299
\end{array}\right] \\
R_{3}=\left[\begin{array}{l}
r_{31} \\
r_{32} \\
r_{33} \\
r_{34} \\
r_{35}
\end{array}\right]=\left[\begin{array}{lllll}
0, & 0.040, & 0.279, & 0.369, & 0.312 \\
0, & 0.039, & 0.288, & 0.374, & 0.299 \\
0, & 0.021, & 0.251, & 0.377, & 0.351 \\
0, & 0.077, & 0.297, & 0.339, & 0.287 \\
0, & 0.115, & 0.305, & 0.305, & 0.275
\end{array}\right]
\end{gathered}
$$

To policy 1 , the grey evaluation weight vector of secondary level index is $W_{2}$, and $W_{2}=(0.43,0.26,0.16$, $0.09,0.06)$. Because of $B_{i}=W_{i} \cdot R_{i}=\left(b_{i 1}, b_{i 2}, b_{i 3}, b_{i 4}, b_{i 5}\right)$, we can get $B_{1}, B_{2}, B_{3}$, and further obtain the evaluation weight matrix $R$, and $R=\left(B_{1}, B_{2}, B_{3}\right)$. Due to $W_{1}=(0.473,0.316,0.211)$, we can get $B=W \cdot R=(0$, $0.0756,0.2746,0.3481,0.3179)$. Finally, we get the comprehensive evaluation value of policy 1 which is denoted by $A_{1}$, and $A_{1}=B \cdot C^{\mathrm{T}}=(0,0.0756,0.2746$, $0.3481,0.3179) \cdot(1,2,3,4,5)^{\mathrm{T}}=3.9571$.

Similarly, we get the comprehensive evaluation value of policy 2 which is denoted by $A_{2}$, and $A_{2}=3.6954$.

\subsection{Analysis on evaluation results and policy suggestion}

By the above evaluation result of $A_{1}>A_{2}$, it can be concluded that the subsidy policy is more effective than the preferential tax policy. There are three reasons as follow. 1) in market cultivation stage, the building owners have the right that whether to retrofit the building. To the building owners, the subsidy policy has more direct effect on and can arouse the enthusiasm further. 2) to multiple subjects in EEEB, subsidies income is a certain and fixed income, but tax benefit income is an expected income. What's more, the preferential tax depends on the earnings before income taxes largely (Liu, 2011). When the earning before income taxes is zero, the preferential tax must be zero. So to the subjects, subsidies income is certain and direct, but the tax benefit income has strong volatility. 3) the utility from the two kinds of income is different to EEEB subject. The subsidies income is obvious benefit, but the tax benefit income is potential benefit. So emotionally, the subsidy policy is easier to be accepted in market cultivation stage.

As a result, it faces the situation of being in the market cultivation stage, and the government should focus on building the subsidy policy. In the range of financial burdens available, the government should further clear incentive object and broaden the scope of incentive, such as the field of technology research and development, demonstration project construction, renewable energy application, propaganda training and education. It also should increase the incentive intensity, such as realizing linkage and joint contribution of multistage government, improving the subsidy ratio. Thirdly, it should revise and renew the motivation model, such as establish policy combination which gives priority to the subsidy policy.

\section{Conclusions}

(1) Based on Grey comprehensive evaluation principles, the paper builds the evaluation model of policies effectiveness of energy efficiency in EEEB. We choose the importance ranking method to determine the weight of evaluation index. The Grey whitening weight function is used to dispose the decentralized information of valuators. The grey cluster theory is used to confirm the evaluation grey class and standards. The establishment of the evaluation model is in favor of detection on policy effects and further policy adjustment, and it also can effectively promotes the standardization construction of technology assessment management and decision-making.

(2) In this paper, the authors compare effectiveness of subsidy policy and preferential tax policy in market cultivation stage and finally get the conclusion that the former is more effective than the latter. The conclusion will provide reference for policy building in further work.

(3) The Grey whitening weight function is an effective method on the situation that evaluation index is difficult to quantify and index data is incomplete. But this method still has some limitations and subjectivities, where in-depth research will be conducted in the future.

\section{References}

Bertoldip, R. (2006). Energy service companies in European countries: current status and a strategy to foster their development. Energy Policy, 34, 1818-1832

Carlsson-Kanyama, A., Linden, A., \& Eriksson, B. (2005). Residential energy behavior: does generation matter. International Journal of Consumer Studies, 29, 239-253

Chen, M. (2012). Establishing evaluation system of the ESCO's core competitiveness based on grey comprehensive evaluation. Zhejiang: Zhejiang Gongshang University, 63-75

Guo, H., Ma, X., \& Shang, L. (2012). Practical and theoretic review on fostering market of energy efficiency in existing buildings. Science \& Technology Progress and Policy, 29, 151-156 
Han, Q., Liu, C., Zhang, Y., \& Jin, Z. (2009). Economic in incentive contract design with a symmetric information in building energy efficiency retrofit. China Civil Engineering Journal, 42, 129-133

James, E. (2004). Public policy. Nanjing: Huaxia Publishing Press, 3544

Jeffery, A., \& Drezner. (1999). Designing effective incentives for energy conservation in the public sector. (Dissertation for the Doctoral Degree). Claremont Graduate University, California.

Liu, Y. (2011). Study on economic incentive for improving energy efficiency of existing residential buildings. Beijing: China Architecture \& Building Press, 92-99

Lu, S. (2007). External analysis and incentive polices of building energy efficiency. Construction Economy, (4), 43-46

Ma, L., Li, H., \& Qi, Y. (2012). Analysis on policy-making process of China's energy-saving performance assessment institution-Taking perspective of central-local interaction. Journal of Public Management, 9(1), 1-8,121

Milou, B., \& Niels, B. (2007). Government regulation as an impetus for innovation: evidence from energy performance regulation in the Dutch residential building sector. Energy Policy, (35), 4812-4825
Wei, X., \& Guo, H. (2014). Research and analysis on domestic and international building practice of policies and regulations system in energy efficiency in existing building. Construction Economy, 35, 68-72

Xu, Z., Guo, H., \& Ren, S. (2009). Analysis on information asymmetry and countermeasure research of energy efficiency market in existing building. Construction Economy, (6), 94-98

Yang, L. (2006). Interest difference and policy game: unique interpretation of relationship between central and the local government. Chongqing Social Sciences, (7), 101-105

Yang, X., Hui, X., \& Zhang, L. (2012). Grey comprehensive evaluation of housing policies effectiveness. China Soft Science, (11), 183192

Zhang, L., \& Wang, Y. (2008). Research on economic incentive polices of energy efficiency in existing building. Construction Economy, (6), 94-96

Zhang, Y., Guo, H.D., Guo, H.G., \& Wang, S. (2009). The evaluation method of government supervision on the main branch of engineering quality in construction phase. Journal of Chongqing Institute of Technology, 23, 57-62 